\title{
Harnessing the Data Revolution: A Perspective from the National Science Foundation
}

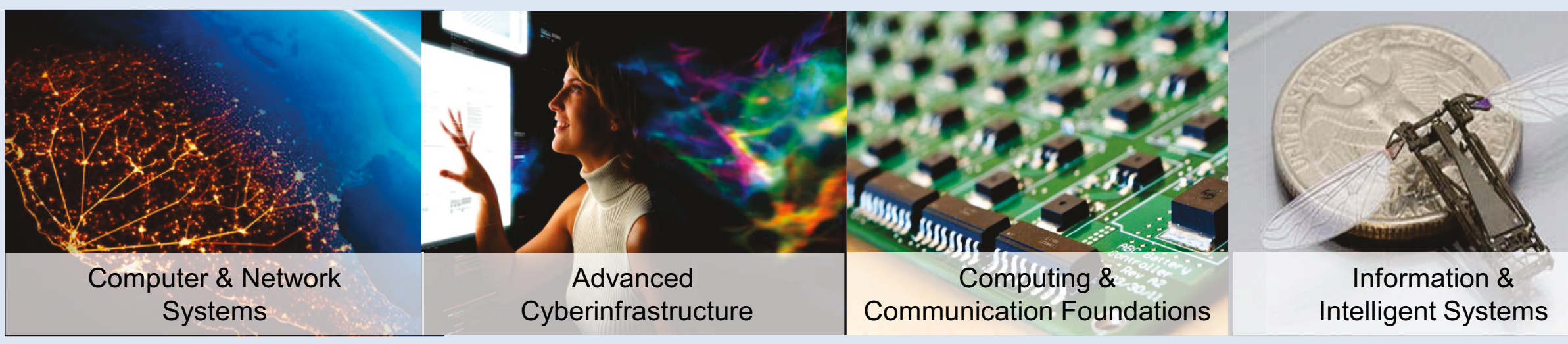

Chaitan Baru

Senior Advisor for Data Science Computer \& Information Science \& Engineering National Science Foundation

NDIC Meeting 


\section{NSF's Big Data / Data Science Programs}

Foundational research to develop new techniques and technologies to derive knowledge from dat

\section{Policy}

New approaches for education and workforce development
New cyberinfrastructure to manage, curate, and serve data to research communities New types of interdisciplinary collaboration, community building 


\section{Big Data / Data Science Research}

\section{Foundational research}

- BIGDATA, QuBBD, CDS\&E, $B D D$, FutureCloud

New cyberinfrastructure to manage, curate, and serve data to research communities

\section{Policy}

New approaches for education and workforce development

New types of inter-disciplinary collaboration, community building

- BIGDATA (cross-Directorate)

- Focus on Foundational Approaches and Innovative Applications

- QuBBD (MPS/DMS and NIH)

- Quantitative Approaches in Biomedical Big Data
- CDS\&E (cross-Directorate)

- Computational and Data Science and Engineering

- BDD (CISE/CCF, IIS)

- Big Data and Disaster Research

- FutureCloud (CISE/CNS) 


\section{Big Data / Data Science Infrastructure}

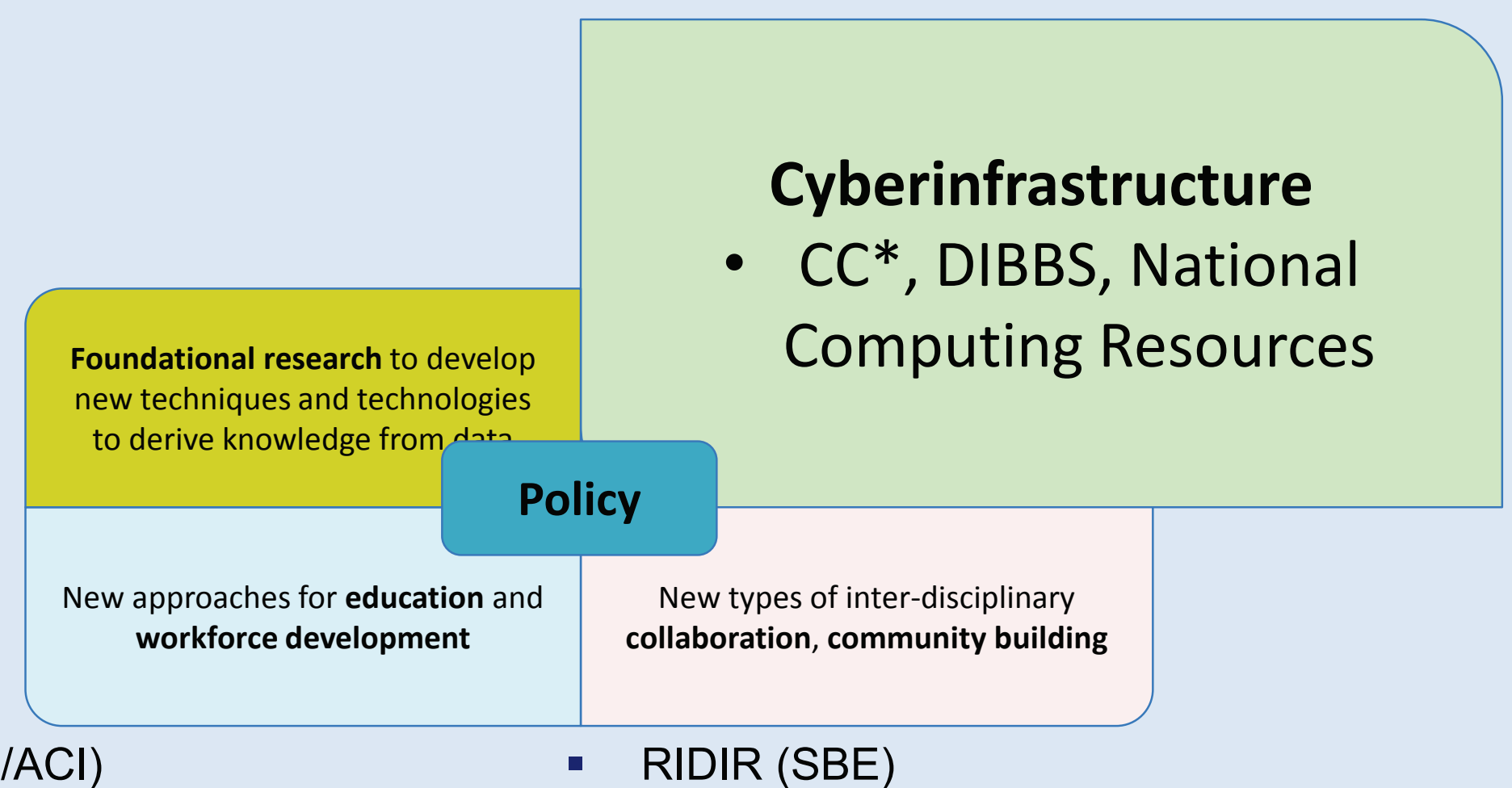

- $\quad$ CC*DNI (CISE/ACI)

- Campus Cyberinfrastructure - Data, Networking, and Innovation Program

- $\quad$ DIBBS (CISE/ACI, with other Directorates)

- Data Infrastructure Building Blocks

- EarthCube (with GEO)
- Resource Implementations for Data Intensive Research in the Social Behavioral and Economic Sciences BCC (EHR)

- Building Community and Capacity in Data Intensive Research in Education 


\section{Big Data / Data Science Infrastructure}

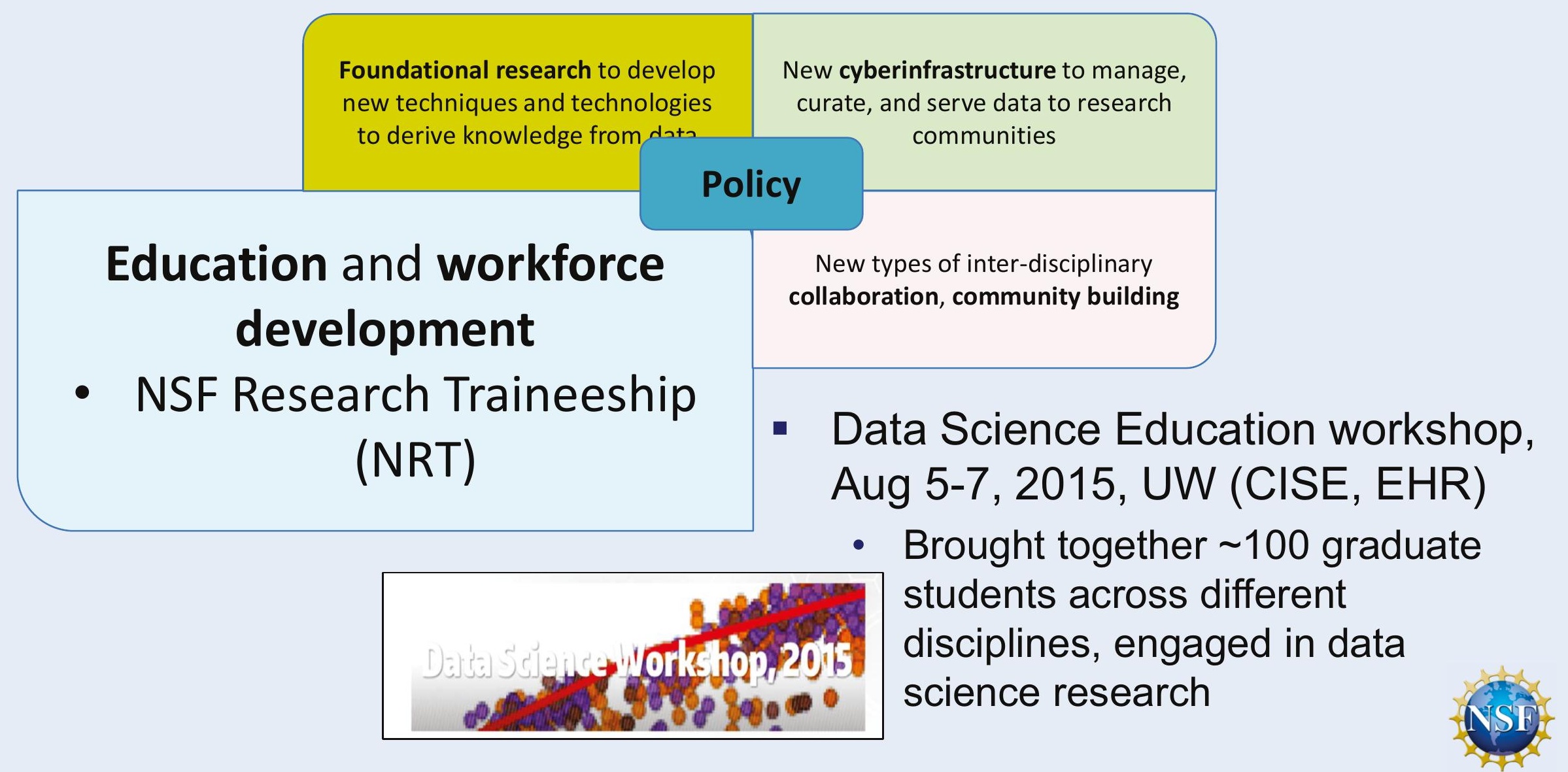




\section{Big Data / Data Science Infrastructure}

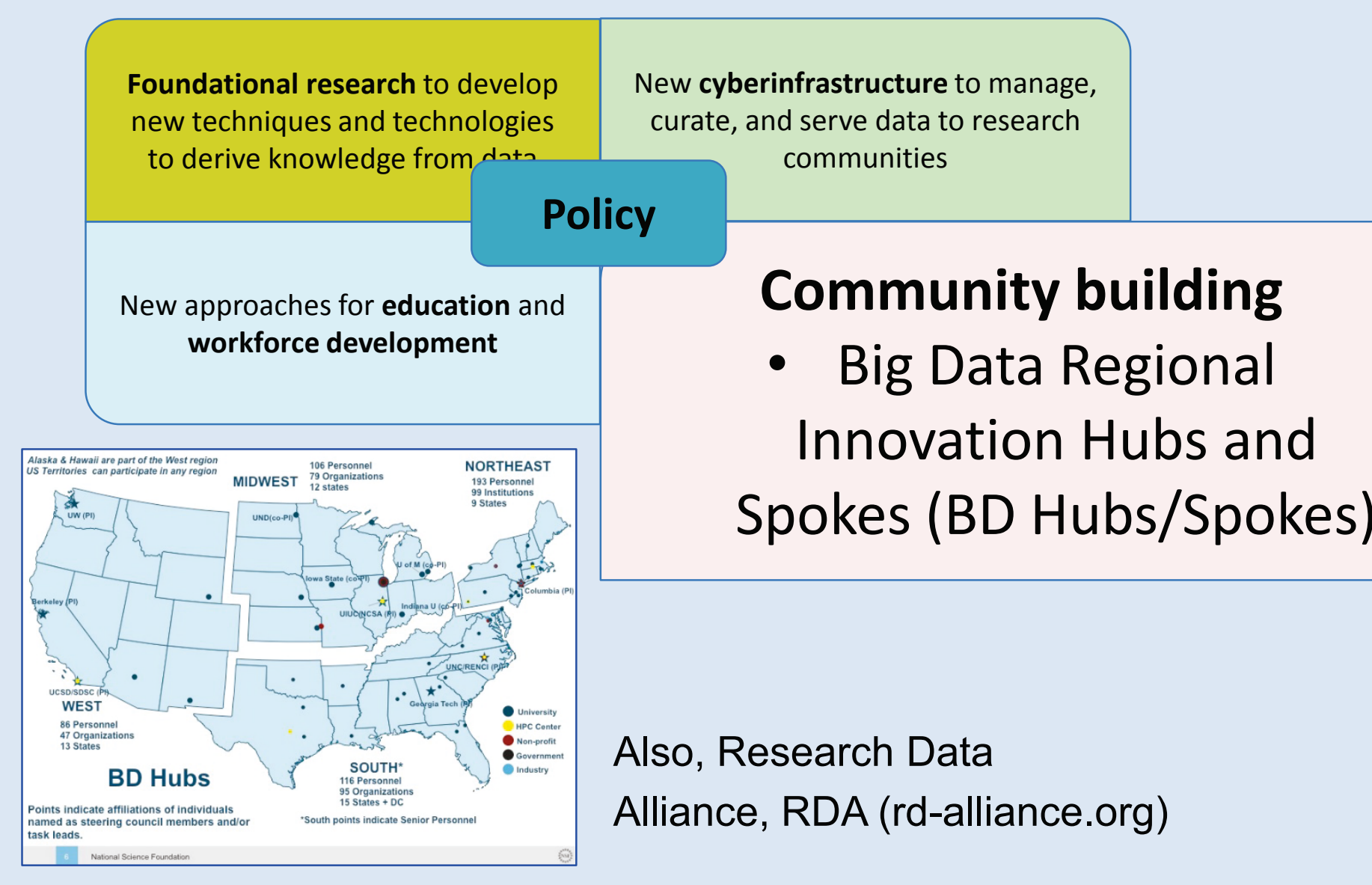




\section{7: Looking Ahead - New Initiatives}

- Smart and Connected Communities (S\&CC)

- Improving quality of life, health, well-being, and learning in communities

- Smart and Autonomous Systems (S\&AS)

- Making possible intelligent physical systems that sense, perceive, and operate in dynamic, uncertain, and unanticipated environments

- Secure and Trustworthy Cyberspace (SaTC)

- Securing our Nation's cyberspace

- Understanding the Brain (UtB)

- Improving understanding of the brain

- National Strategic Computing Initiative (NSCl)

- Maximizing benefits of HPC for scientific discovery and economic competitiveness

- Data for Scientific Discovery \& Action (D4SDA)

- Enabling $21^{\text {st }}$ century science, engineering, and education to move toward effective use of digital data to advance discovery 


\section{$\mathrm{NSCl}$ and Data Science:}

\section{Two related national imperatives}

- High Performance Computing and Data Science in support of science and engineering discovery and competitiveness

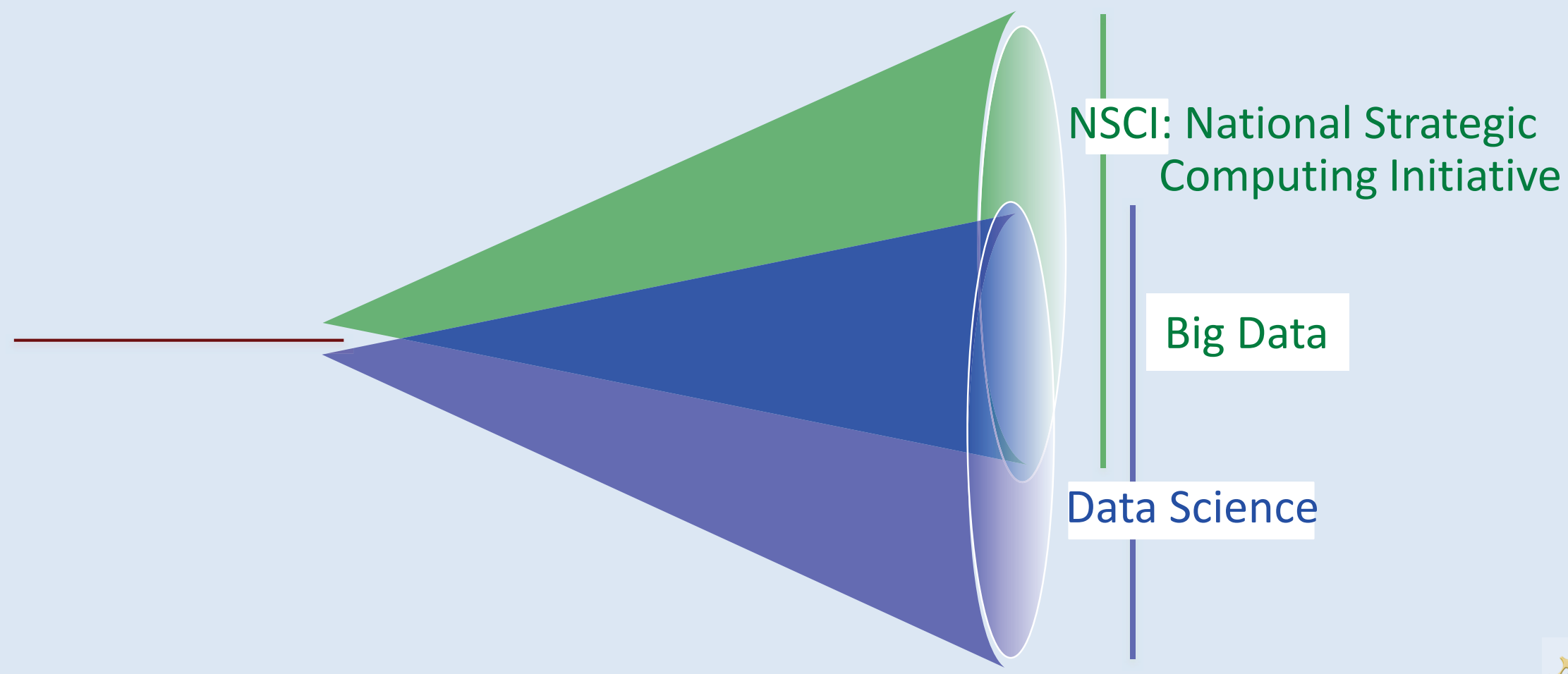




\section{National Strategic Computing Initiative (NSCl)}

Maximizing benefits of HPC for scientific discovery

and economic competitiveness

CISE Investment: \$19.70 M (2017)

- Partnership among CISE (co-lead), MPS (co-lead), ENG, and GEO

- Aligns with Executive Order 13702, Creating a National Strategic Computing Initiative

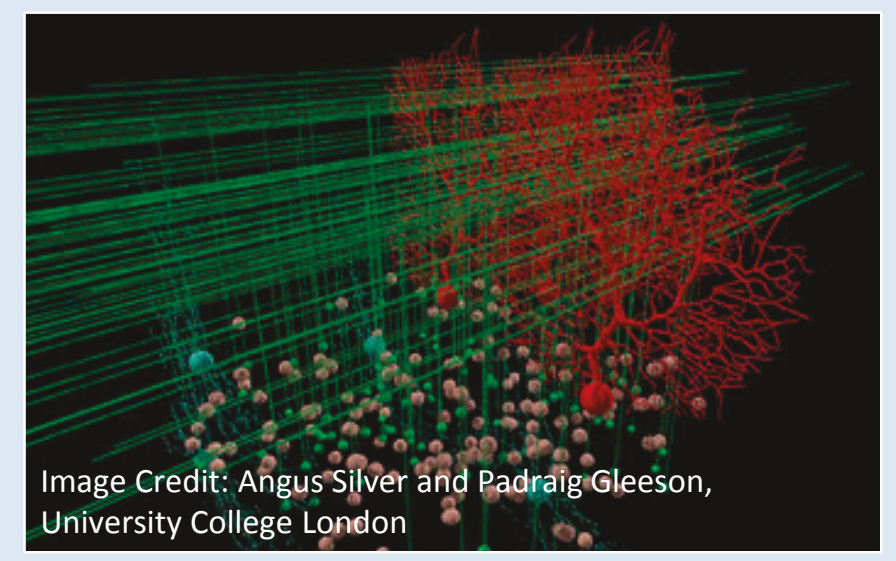

- NSF - with CISE leading - plays a central role in:

- Scientific discovery advances

- Broader HPC ecosystem for scientific discovery

- Workforce development

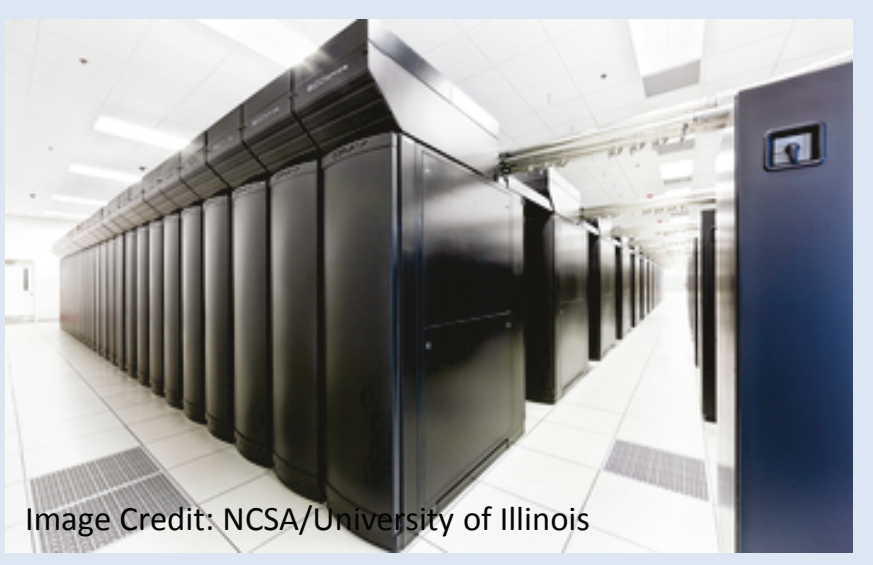




\section{Data for Scientific Discovery \& Action (D4SDA)}

Enabling $21^{\text {st }}$ century science, engineering, and education to move toward effective use of digital data to advance discovery

CISE Investment: \$19.60 M (2017)

- Aims to:

- Promote foundational research in critical techniques, technologies

- Provide innovative, reusable data and knowledge infrastructure to support data-intensive science

- Enable/incent science community to address data governance, lifecycle issues

- Educate data-savvy workforce of scientists, engineers, educators 


\section{NSF "Big Ideas"}

\section{Science}

Home

News

Journals

Topics

Careers

Search

Latest News Sciencelnsider ScienceShots Sifter From the Magazine About News Quizzes

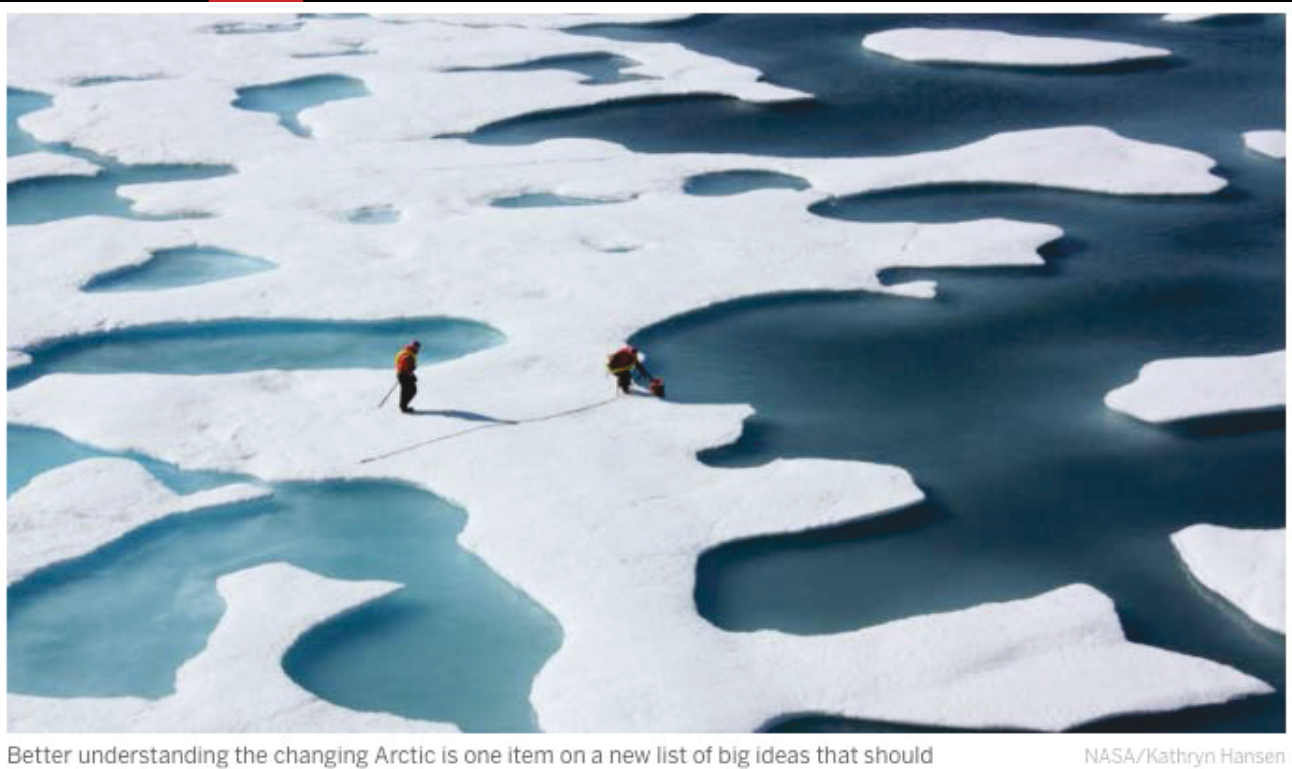

Better understanding the changing Arctic is one item on a new list of big ideas that should shape the National Science Foundation's work.

NSF director unveils big ideas, with an eye on the next president and Congress 


\section{NSF "Big Ideas"}

- Catalyze interest, investment in fundamental research

- Generate broad public appeal and attract partnerships with industry, private foundations, and academia

- Cutting-edge research agenda, appropriate for NSF

- Process: directorate discussions, white papers, $A D$ retreat, subsequent collaborative refinement 
NSF "Big Ideas"

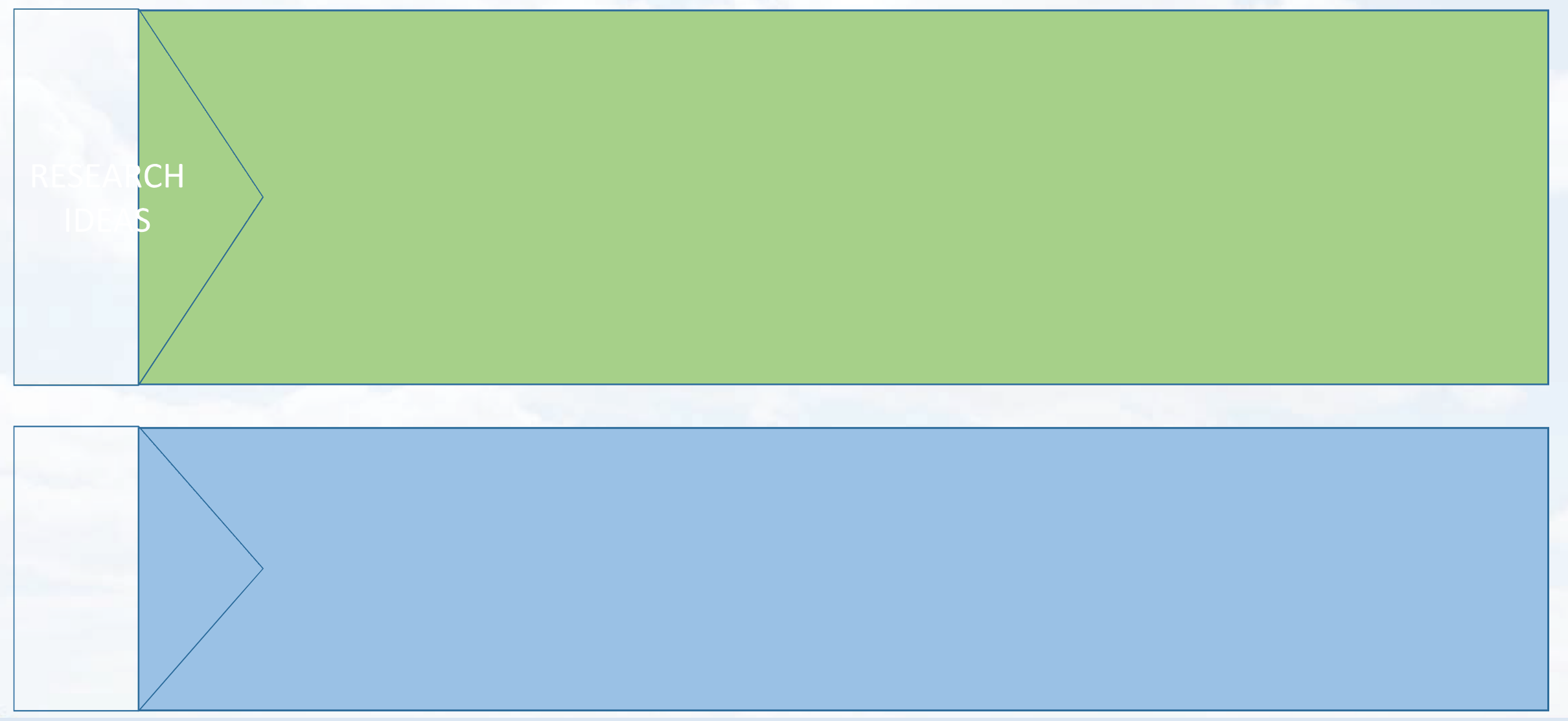

CISE will play a key role in many of these Big Ideas 


\section{Harnessing the Data Revolution}

AD Retreat: CISE white paper

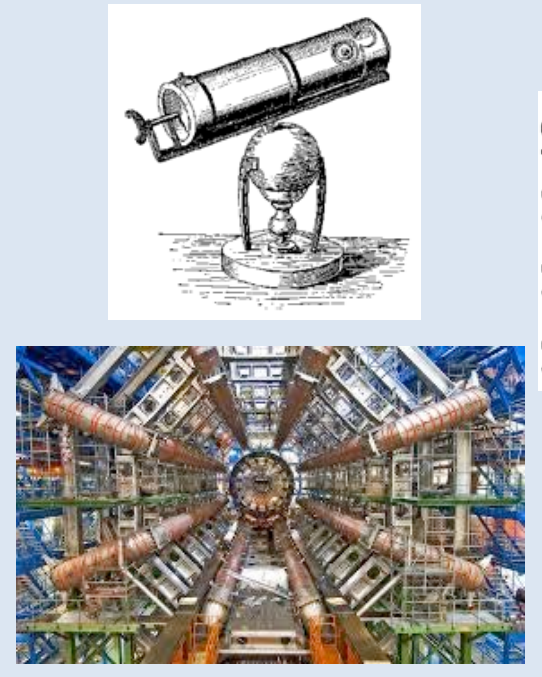

$$
\begin{aligned}
& \oint \mathrm{E} \cdot d \mathrm{~A}=\frac{q_{\text {enc }}}{\varepsilon_{0}} \\
& \oint \mathrm{B} \cdot d \mathrm{~A}=0 \\
& \oint \mathrm{E} \cdot d \mathrm{~s}=-\frac{d \Phi_{\mathrm{B}}}{d \mathrm{t}} \\
& \oint \mathrm{B} \cdot d \mathrm{~s}=\mu_{0} \varepsilon_{0} \frac{d \Phi_{\mathrm{E}}}{d \mathrm{t}}+\mu_{0} i_{\text {enc }} \\
& \frac{\partial \rho}{\partial t}+\frac{\partial}{\partial x_{i}}\left(\rho u_{i}\right)=S_{m} \\
& \frac{\partial}{\partial t}\left(\rho u_{i}\right)+\frac{\partial}{\partial x_{j}}\left(\rho \mu_{i} u_{j}\right)= \\
& -\frac{\partial p}{\partial x_{i}}+\frac{\partial r_{i j}}{\partial x_{j}}+\rho g_{i}+F_{i}
\end{aligned}
$$
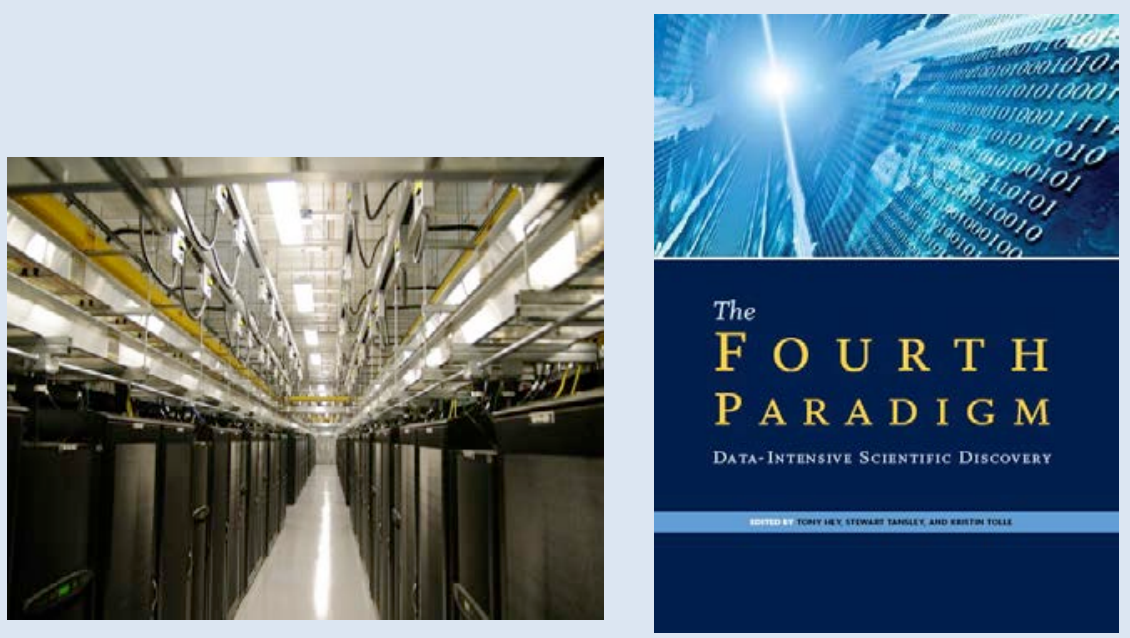

\section{Experimental Theoretical}

Computational

\section{Data}

Vision: move beyond isolated, standalone approaches for data science, services and infrastructure towards a cohesive, federated, national-scale approach that will harness the data revolution and transform U.S. science, engineering, and education over the next decade and beyond 


\section{Data: critical across all of science}

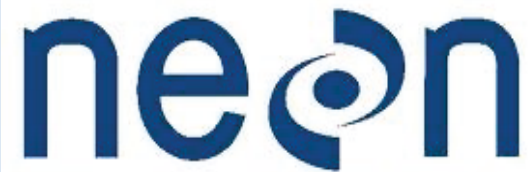

National Ecological Observatory Network, Inc.

\section{BIGDATA}
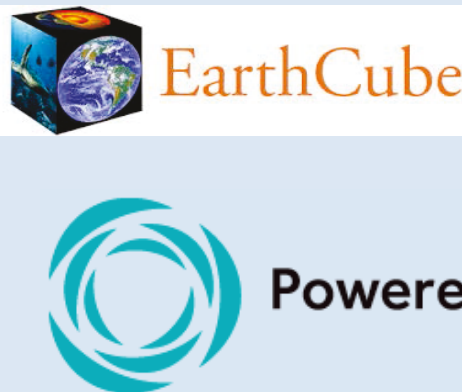

Powered by iPlant

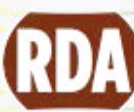

Research Data Sharing without barriers

H DATA ALLIANCE

National Science Foundation Research Traineeship (NRT) Program
NSF’S PUBLIC ACCESS PLAN: NSF 15-52

Today's Data, Tomorrow's Discoveries

Increasing Access to the Results of Research Funded by the National Science Foundation

National Science Foundation
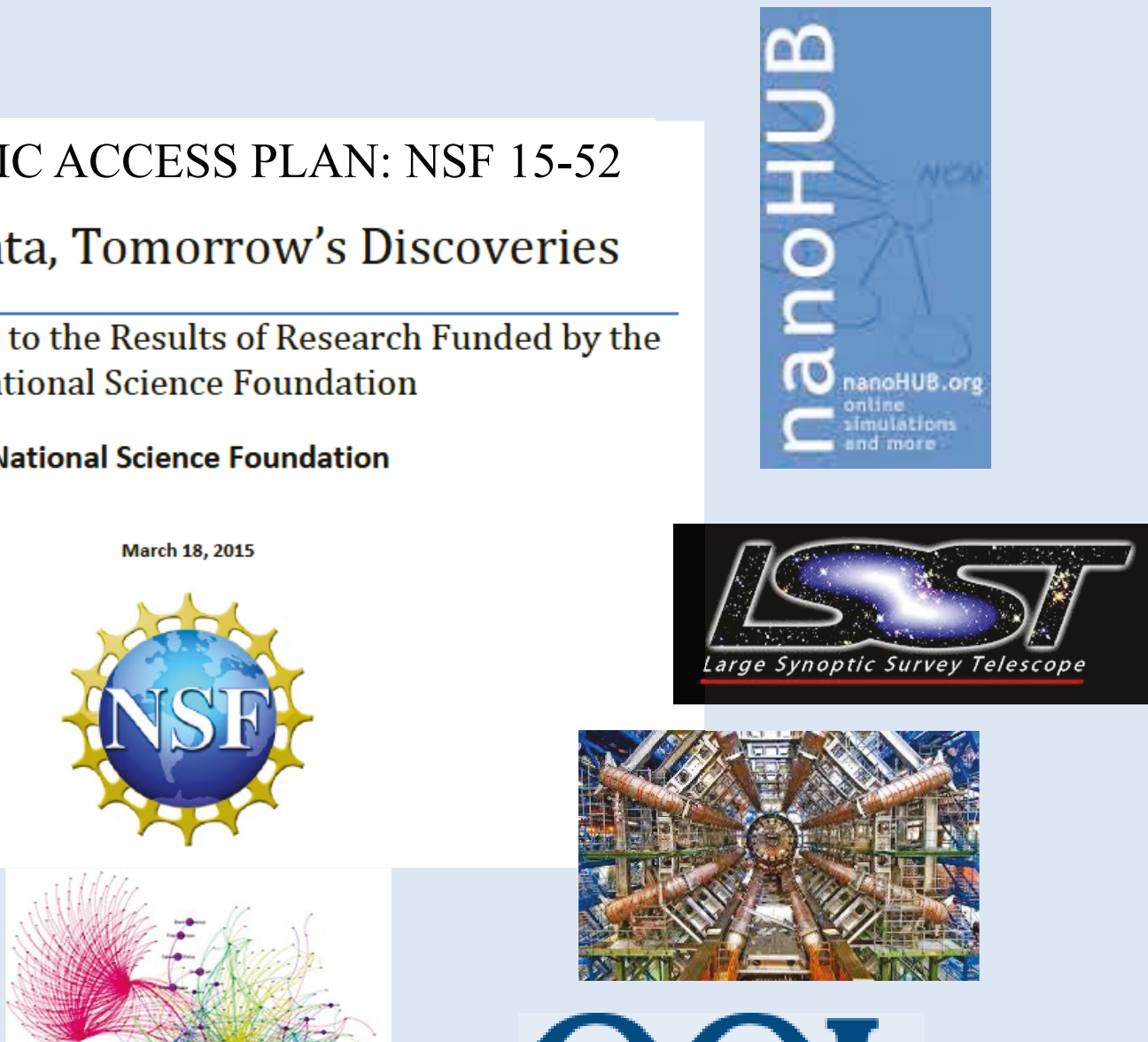

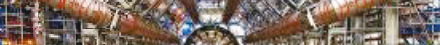

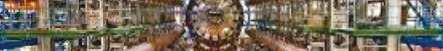

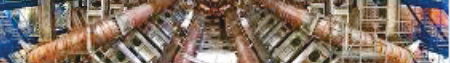

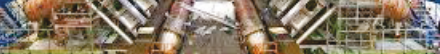

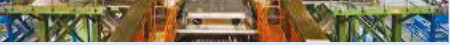

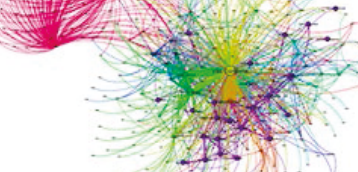

Sócial networks

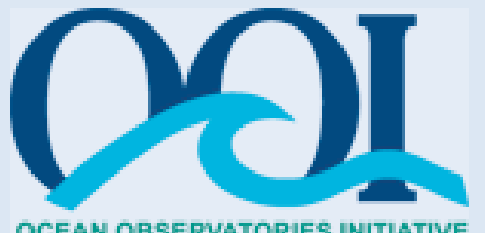




\section{Harnessing the Data Revolution*}

- fundamental research in mathematics, statistics, computer and computational science: data-driven discovery, decision-making

- fundamental research on data topics: data discovery and integration, predictive analytics, data mining, machine learning; data semantics, open data-centric architectures and systems, reproducibility, privacy and protection, human-data interface

- engagement of the research domains supported across NSF: use advances in data science and $\mathrm{Cl}$ to further research

- embodiment of these innovations in a robust, comprehensive, open, science-driven, $\mathrm{Cl}$ ecosystem: accelerating a broad spectrum of data-intensive research, including large-scale, MREFC facilities

- development and evaluation of innovative learning opportunities and educational pathways, grounded in an education-researchbased understanding of needs 


\section{A vision for research cyberinfrastructure}

An open national research $\mathrm{Cl}$ architecture

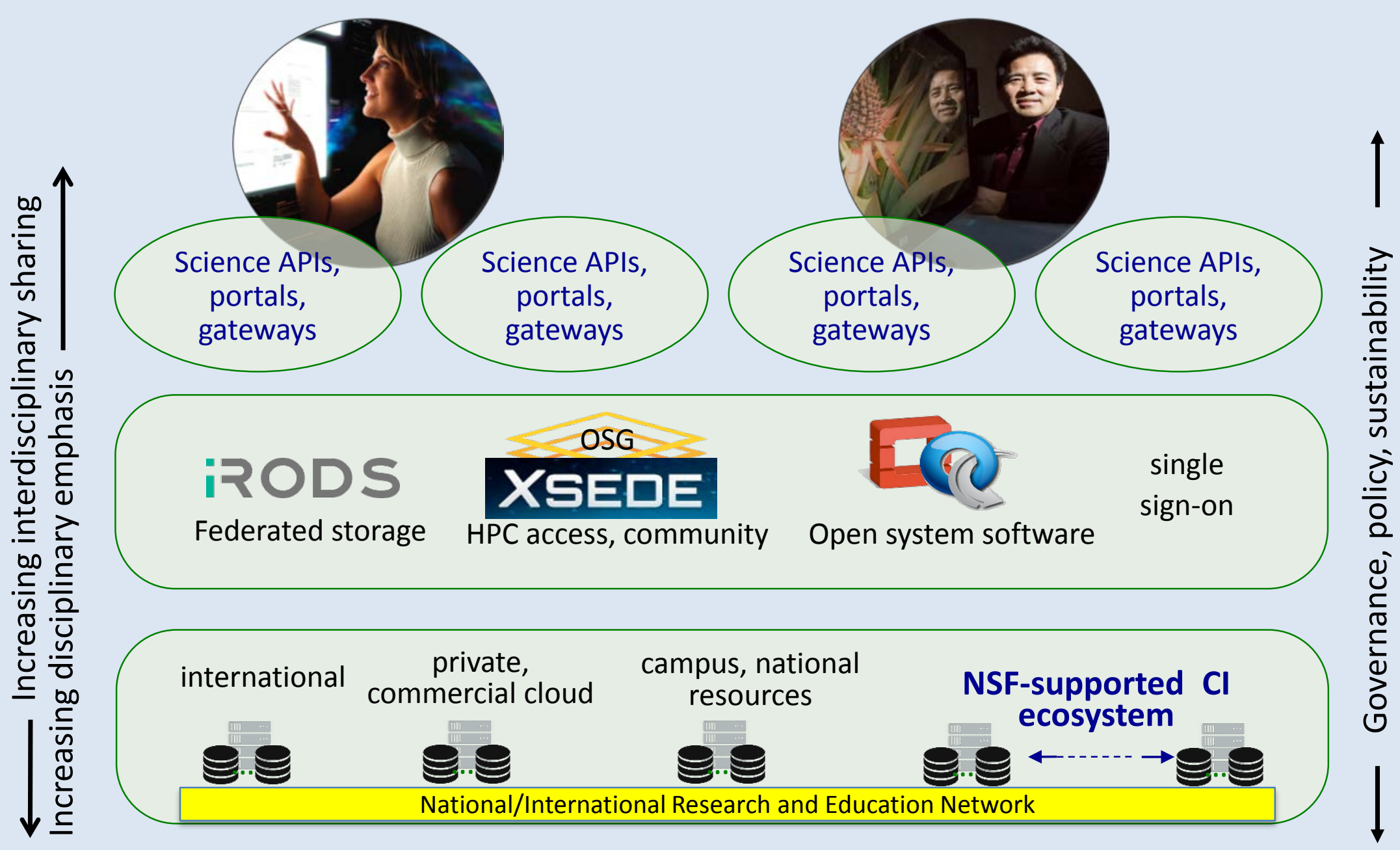




\section{A vision for research cyberinfrastructure}

Architecting an open national data infrastructure

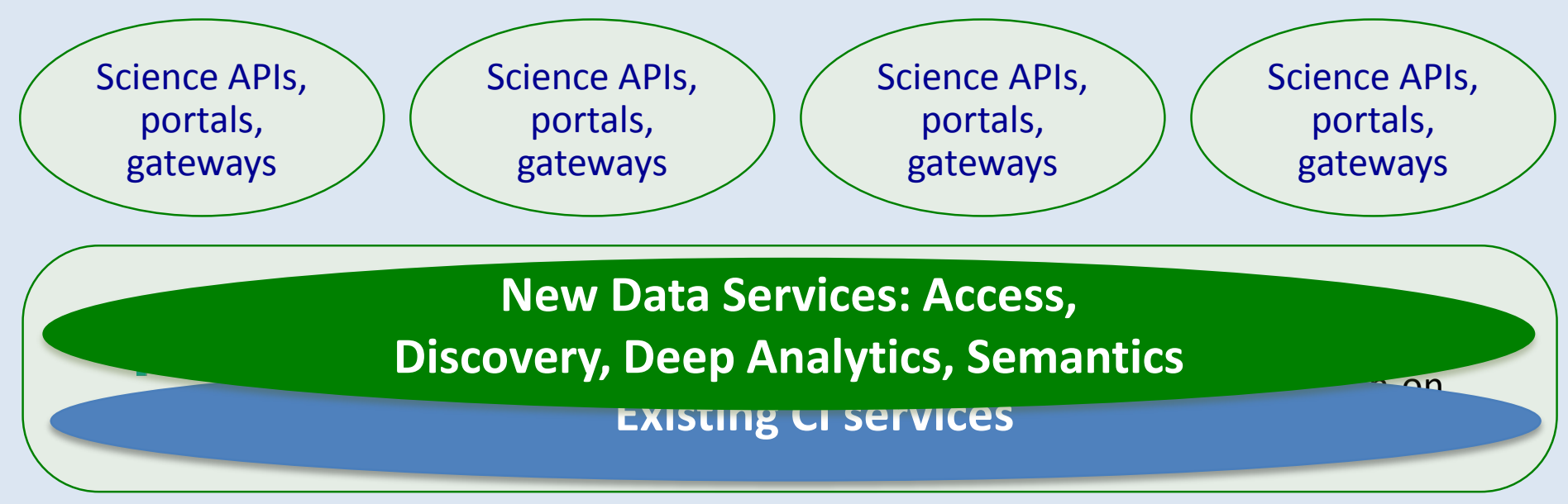

$$
\text { international } \begin{gathered}
\text { private, } \\
\text { commercial cloud }
\end{gathered}
$$

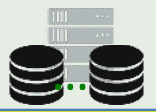

campus, national resources

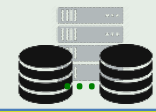

NSF-supported $\mathrm{Cl}$ ecosystem 


\section{A vision for research cyberinfrastructure}

Architecting an open national data infrastructure

\section{Enabling and accelerating science drivers, including NSF initiatives \& facilities}

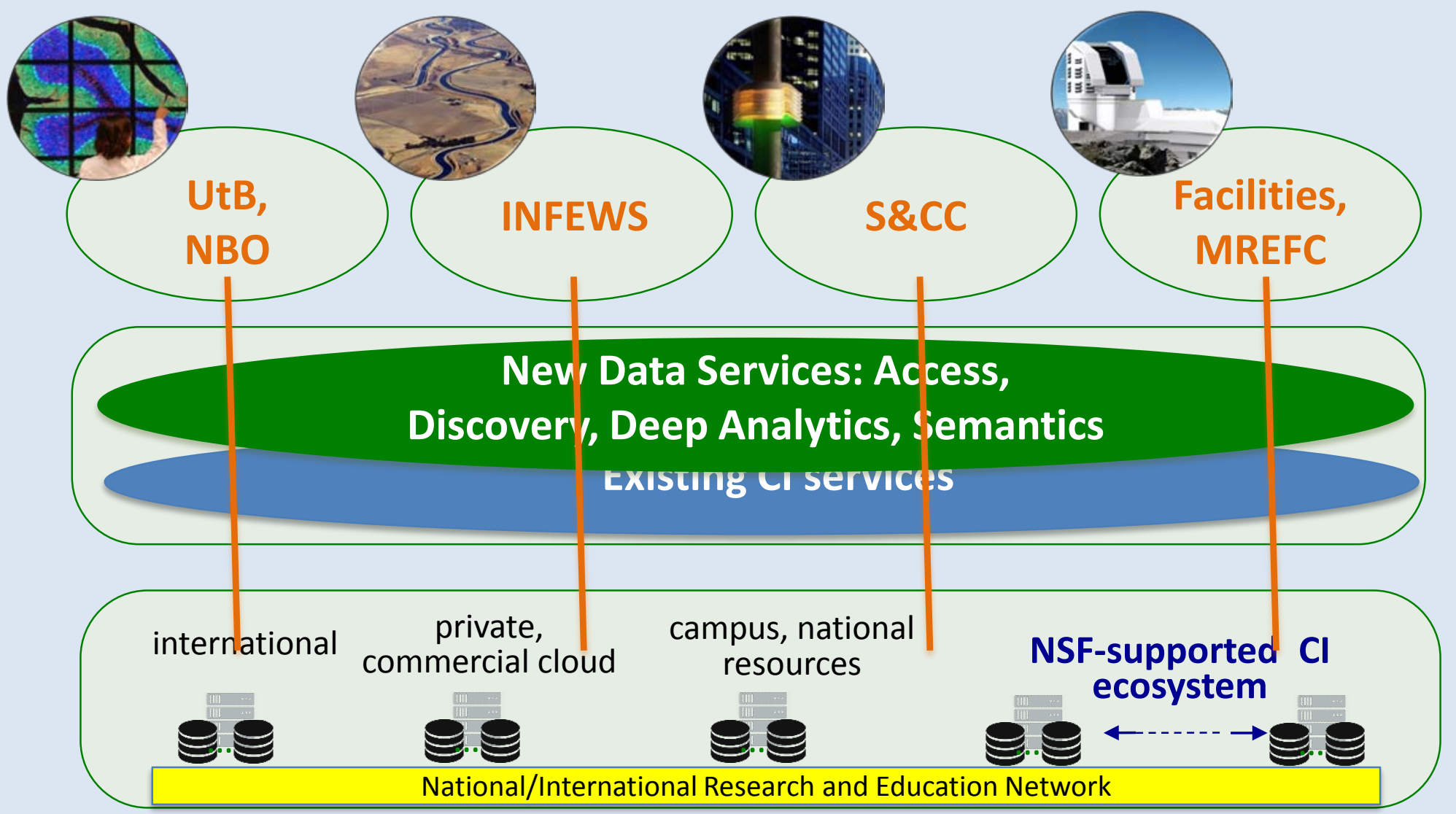




\section{We are ready!}

- NSF has help set the foundation:

- CIF21 initiative

- BIGDATA, ML investments

- EarthCube

- Research Data Alliance (RDA)

- Data Hubs (and Spokes) investments

- Resource Implementations for Data Intensive Research in the SBE (RIDIR)

- DataONE

- iDigBio

- Public Access Plan

- Federal government partners

- Industry, state/local partners (e.g., Data Hubs) 


\section{Urgency: A national imperative}

Research

Just as computational science transformed scientific research in the $20^{\text {th }}$ century, so too can data science fundamentally transform scientific research in this century.

Just as HPC and NSFNET enabled and accelerated new science and engineering

Research research in the $20^{\text {th }}$ century, so too can Infrastructure national data infrastructure enable and accelerate new science and engineering in this century.

If not us, who? If not now, when? 


\section{Some Related Events / Activities}

- Recent meetings

- US-UK Health Data Science Workshop, March 1-2, 2016, NIH Campus, Bethesda, MD. Hosted by Stanford University, in conjunction with the Research Councils of the United Kingdom (RCUK), NIH, NSF

- NSF BIGDATA PI Meeting, April 20-21, Arlington, VA

- NSF Workshop on TFODS: Theoretical Foundations of Data Science, April 28-30, 2016

- Upcoming events

- CATS Workshop on Causal Inference from Big Data, Washington DC, June 2016

- NAS Workshops on Envisioning the Data Science Discipline: The Undergraduate Perspective, Washington DC, 2016

- NITRD Workshop on Metrics for Assessing the Value of Digital Data Repositories, Washington DC, 2016

- BD Hubs Annual Meeting, Washington DC, 2016 


\section{An amazing time to be in CISE!}

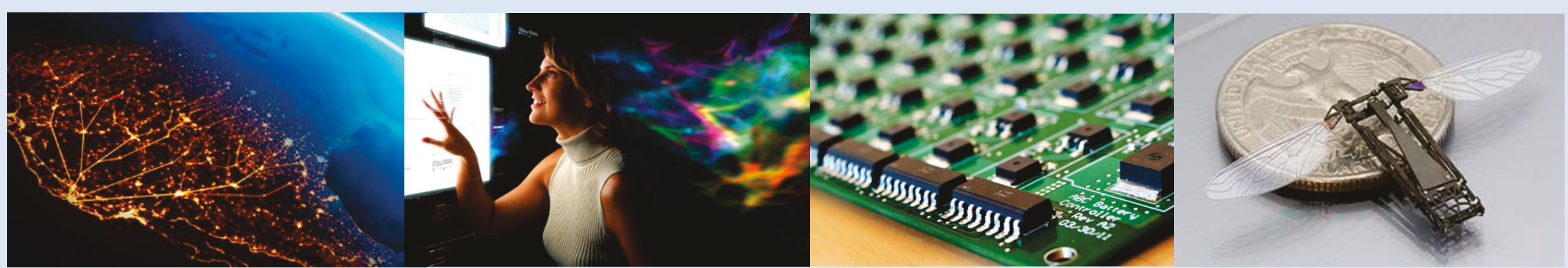

- Ubiquity: computing seems to be everywhere: science and engineering, workforce, societal

- Engagement: with many communities

- Urgency: rapidly expanding and evolving field opportunity(!) in a time of fiscal uncertainty 


\section{Thanks!}

- Chaitan Baru, cbaru@nsf.gov, (703) 292-4541 


\section{Smart \& Connected Communities (S\&CC)}

Improving quality of life, health, well-being, and learning in communities

CISE Investment: \$16.50 M

- Partnership among CISE, EHR, ENG, GEO, and SBE

- Network of regional research hubs to advance fundamental research

- Advanced networking; physical sensors/devices; large-scale data management, analysis, and decision making, security, privacy

- Builds on previous investments in Urban Science and US Ignite
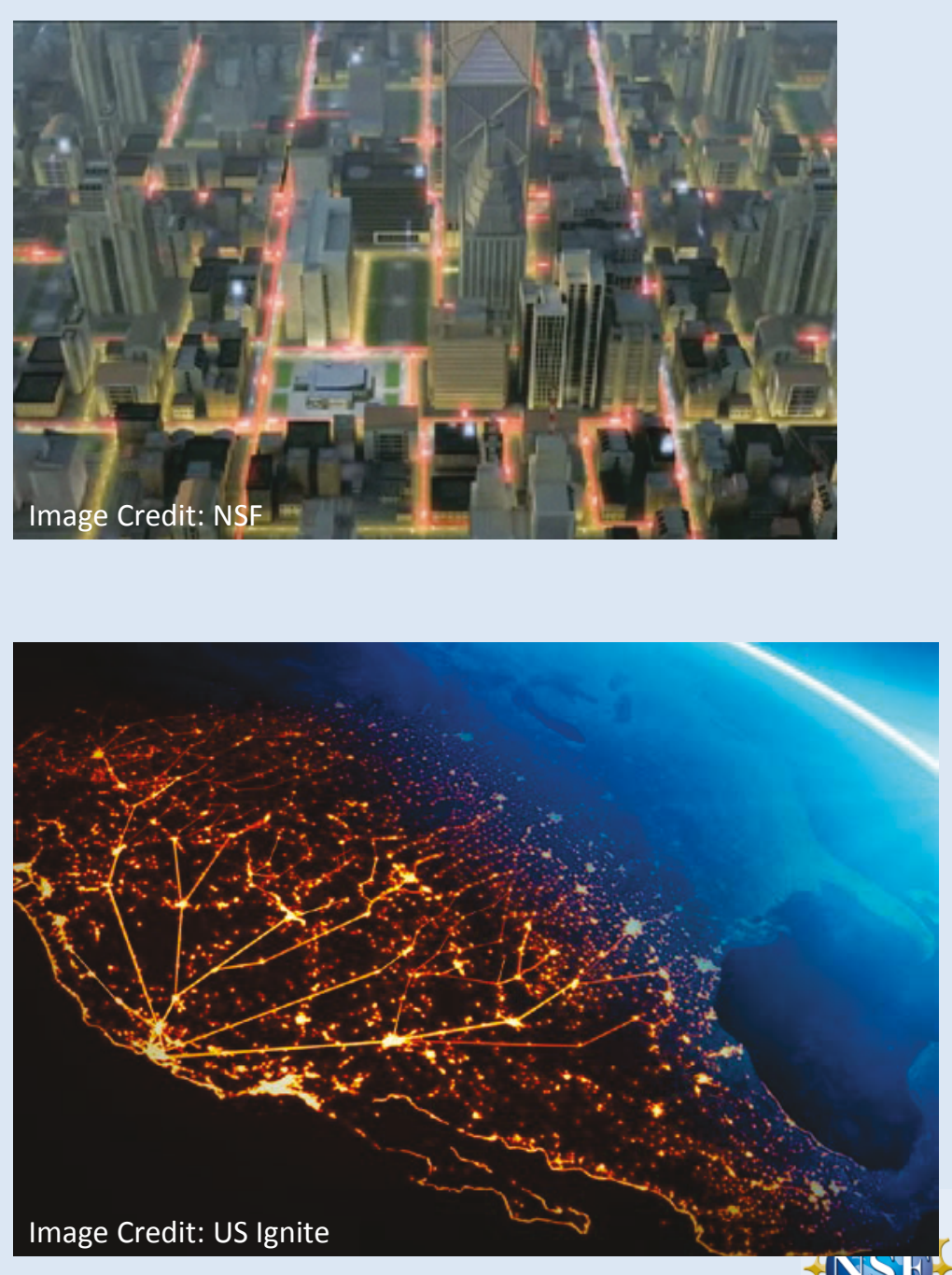


\section{Smart \& Autonomous Systems (S\&AS)}

Making possible intelligent physical systems that sense, perceive, and operate in dynamic, uncertain, and unanticipated environments

- Advances interstices of NRI and CPS

- National Robotics Initiative (NRI): "corobots" - robots that work alongside, or cooperatively with, people

- Cyber-Physical Systems (CPS): deeply integrating computation, communication, control into physical systems, typically with provably correct behavior

- Exceeding today's capabilities in

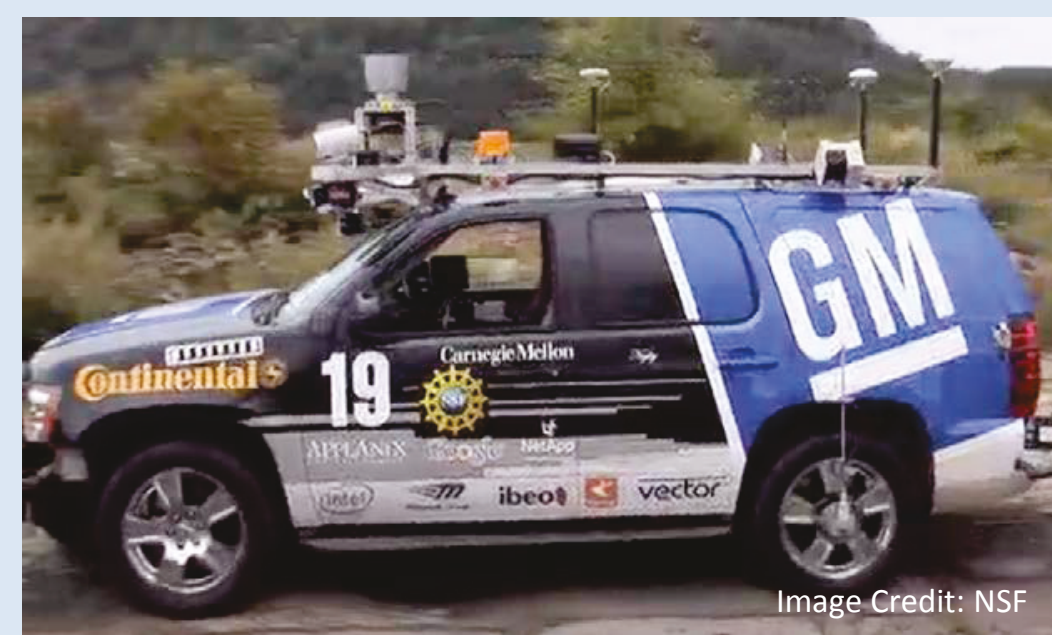
adaptability, autonomy, functionality, efficiency, reliability, safety, usability, recoverability, recyclability 


\section{Secure and Trustworthy Cyberspace (SaTC)}

Securing our Nation's cyberspace

CISE Investment: $\$ 70.50 \mathrm{M}$

- Partnership among CISE, EHR, ENG, MPS, and SBE

- Aligns with 2016 Federal

Cybersecurity Research and

Development Strategic Plan

- CISE emphases:

- Secure and Trustworthy Cyberspace program

- NSF/Intel Partnership on Cyber-Physical Systems Security and Privacy (CPS-Security)

- Emerging areas:

- Experimental testbeds

- Science of privacy

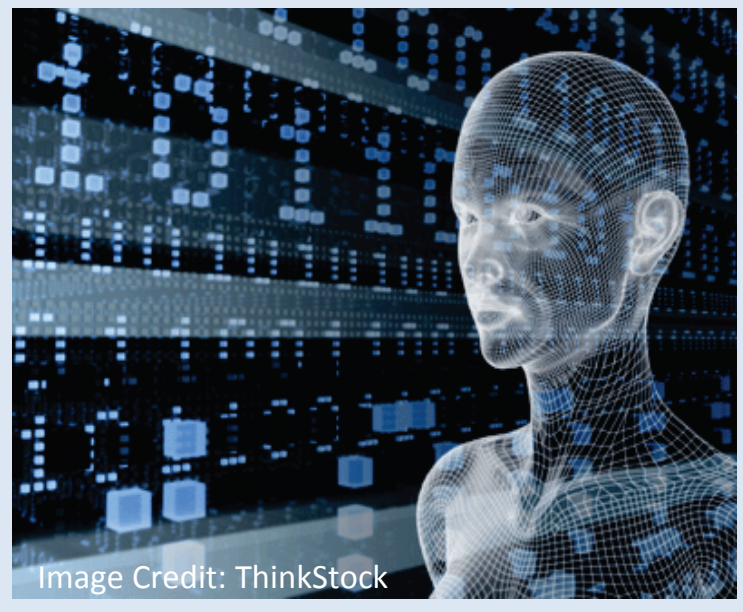

- Network and cloud security

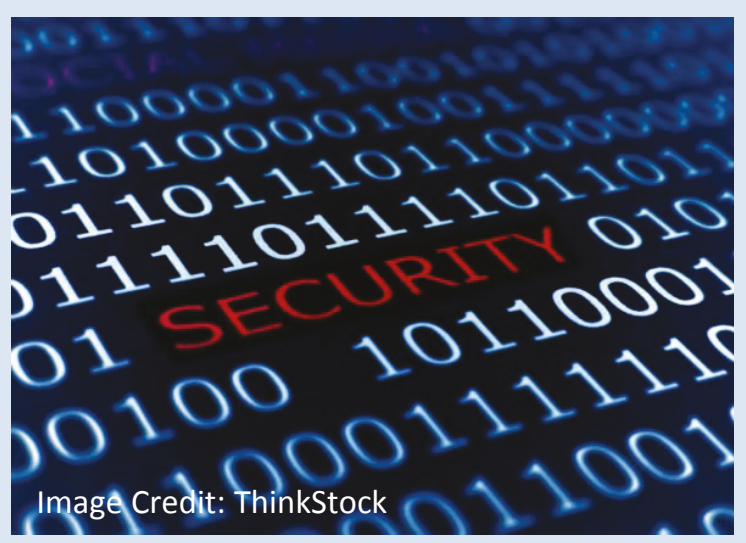




\section{Understanding the Brain (UtB)}

Improving understanding of the brain

CISE Investment: \$23.58 M

- Partnership among all NSF directorates

- Includes the BRAIN Initiative

- National Brain Observatory

- Partnership among CISE, BIO, EHR, ENG, MPS, and SBE

- Facilitate coordination of largescale data collection efforts nationally and internationally to advance understanding of brain function
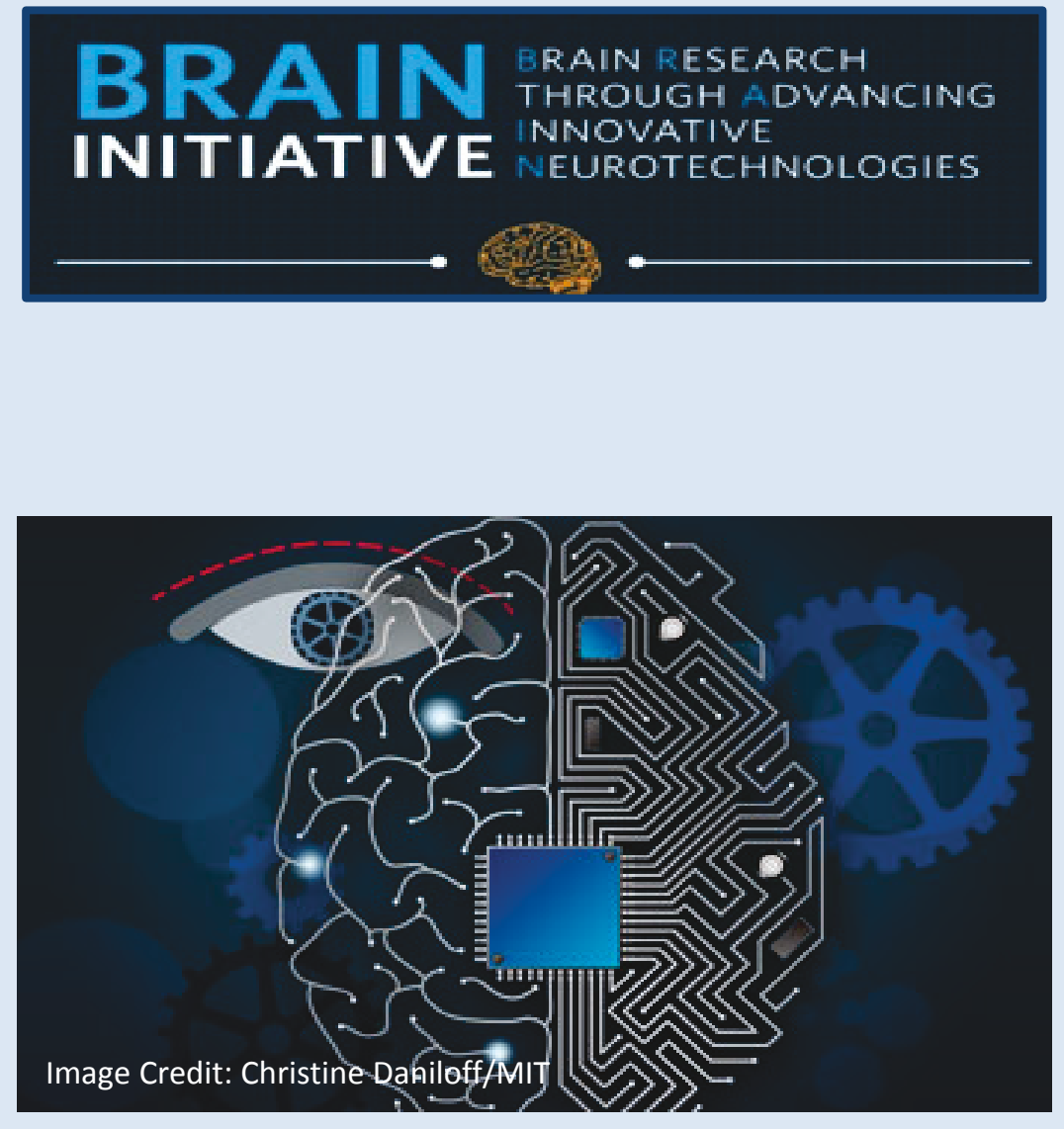